\title{
Interface Shear Strength at Joints of Ultra-High Performance Concrete Structures
}

\author{
Young-Jin Kim ${ }^{1}$, Won-Jong Chin ${ }^{1}$ and Se-Jin Jeon ${ }^{2 *}$
}

\begin{abstract}
When ultra-high performance concrete (UHPC) is fabricated as precast members such as in a UHPC segmental bridge, the joint design between the precast members can significantly affect the overall integrity and safety of the structure. Therefore, the structural behavior of the UHPC joint was experimentally investigated in this study with test variables including joint type, number and height of shear keys, type of filler, curing temperature, and lateral compressive stress. The UHPC considered in this study is the K-UHPC developed in Korea with a specified compressive strength as high as $180 \mathrm{MPa}$ and high flowability. The joint shear strengths affected by the test variables were investigated in detail. The test results were also compared with two representative predictive equations for interface shear strength to determine an appropriate equation for the joint design of UHPC. These equations did not match well with the test data because they were originally proposed for normal strength concrete. However, the JSCE equation could be improved by modifying a coefficient to show good agreement with the test especially in the case of the dry joint with epoxy application.
\end{abstract}

Keywords: ultra-high performance concrete, interface shear strength, dry joint, wet joint, shear key, push-off test

\section{Introduction}

Ultra-high performance concrete (UHPC) has superior mechanical properties in terms of compressive and tensile strengths, ductility, toughness, flowability, durability, etc., when compared to ordinary concrete. Therefore, the use of UHPC can lead to an efficient design with sections of reduced size and reduced quantities of materials, and to a longer service life of the structure, all of which can contribute to reducing the life-cycle cost of structures. UHPC can be either fabricated as precast members at a plant or cast in-place at a construction site in a similar way to ordinary concrete. The precast type construction has recently been increasingly more preferred to conventional cast-in-place construction due to its accelerated and safer construction, high quality, aesthetics, and durability of structure. In precast-type UHPC structures such as those shown in Fig. 1, structural behavior at the joints

\footnotetext{
*Correspondence: conc@ajou.ac.kr

${ }^{2}$ Department of Civil Systems Engineering, Ajou University, 206,

Worldcup-ro, Yeongtong-gu, Suwon-si, Gyeonggi-do 16499, Republic of Korea

Full list of author information is available at the end of the article

Journal information: ISSN 1976-0485 / eISSN 2234-1315
}

between the precast segments can significantly affect the overall safety and serviceability of the structure.

Several measures have therefore been taken to ensure the continuity and integrity at the joints (Mohsen and Hiba 2007; Turmo et al. 2006). In general, two types of joints have been applied to precast UHPC structures similarly to ordinary concrete structures: a wet joint, where the joint is cast in-place with a selected material (Ishii et al. 2008; Matsubara et al. 2008; Park et al. 2013) and a dry joint, where the surfaces of two precast segments formed by match-casting are in direct contact. Figure 1a shows an example of the wet joint cast in-place with UHPC. The dry joints include the epoxy-coated or epoxy-glued joints that improve the resistance to external loads and prevent the penetration of water from outside. Although the epoxy-coated joint is classified as a wet joint in some documents, the term 'dry joint' is consistently used in this study for match-cast joints regardless of application of the epoxy. Regardless of the type of joint employed, shear keys are often used at the joint to assist in carrying the design shear force at that location.

The failure mode and cracking pattern of the shearkeyed joint made of normal strength concrete have 


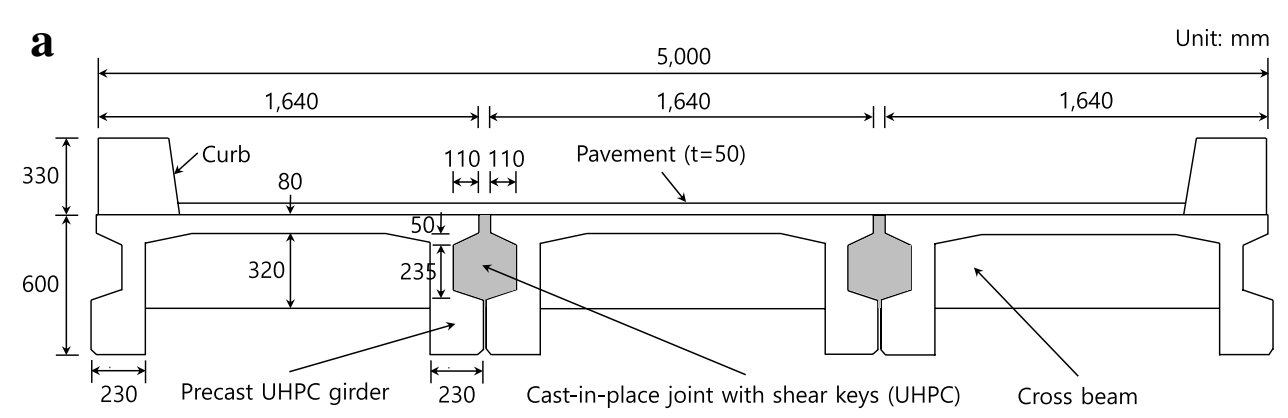

b

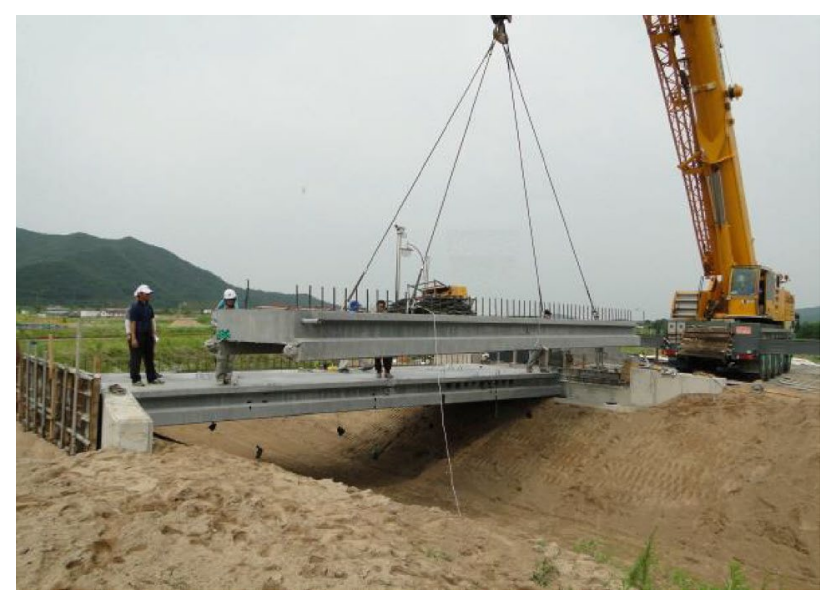

Fig. 1 Construction of a precast UHPC bridge (Andong Pi-girder bridge in Korea). a Section view including joints. b Erection of precast segments.

been investigated in a number of studies (Mohsen and Hiba 2007; Turmo et al. 2006). Shin (2016) investigated the failure mode of UHPC shear key made in the form of a dry joint without epoxy, where the contribution of steel fibers was noted. In particular, there were attempts to analytically investigate the shear-off failure modes of shear-keyed dry joint using finite element method to verify and complement the test results (Kaneko 1992; Shamass et al. 2014).

Despite the above countermeasures and previous studies, particularly for the UHPC structures with ultra-high strength, the joint is prone to be a weak point of a structure unless the strength at the joint is sufficiently verified through a number of tests. Therefore, structural behavior of a UHPC joint was experimentally investigated in this study with the test variables including joint type, number and height of shear keys, type of filler, curing temperature, and lateral compressive stress. Also, the test results were compared with several predictive equations for interface shear strength to determine an appropriate equation for the joint design of UHPC members.

\section{Test of UHPC Joints}

\subsection{Characteristics of K-UHPC}

Although various mix proportions of UHPC have been proposed depending on the target properties, the $\mathrm{K}$-UHPC developed in Korea is the main focus in this study (Korea Concrete Institute 2012; Korea Institute of Civil Engineering and Building Technology 2012). Table 1 presents the specific mix proportion of the K-UHPC which is expressed as a ratio of mass. The mixture consists of cement, silica fume, filling powder, fine aggregate,

Table 1 Mix proportion of K-UHPC (ratio of mass).

\begin{tabular}{llllllll}
\hline $\begin{array}{l}\text { Water-to- } \\
\text { binder ratio }\end{array}$ & Cement & Silica fume & Filling powder & Fine aggregate & $\begin{array}{l}\text { Shrinkage } \\
\text { reducing agent }\end{array}$ & $\begin{array}{l}\text { Expansive } \\
\text { agent }\end{array}$ & $\begin{array}{l}\text { Superplasticizer } \\
\text { Steel fiber } \\
\text { (volume } \\
\text { fraction) }\end{array}$ \\
\hline 0.2 & 1 & 0.25 & 0.3 & 1.1 & 0.01 & 0.075 & $1.5-2 \%$ \\
\hline
\end{tabular}


shrinkage reducing agent, expansive agent, superplasticizer, and steel fibers. Coarse aggregates are not included in this mixture. The steel fibers have a diameter of $0.2 \mathrm{~mm}$ and a tensile strength of more than $2000 \mathrm{MPa}$. The length of the fibers can be selected among 13, 16, and $20 \mathrm{~mm}$ depending on the required tensile characteristics. The specified compressive strength, cracking strength, and tensile strength of K-UHPC are as high as 180, 9.5, and $13 \mathrm{MPa}$, respectively. The shape and dimensions of these test specimens and test methods are specified in design recommendations for K-UHPC (Korea Concrete Institute 2012) in detail. The specimen shape for compressive strength is a cylinder with $100 \mathrm{~mm}$ diameter and $200 \mathrm{~mm}$ height. Cracking strength and tensile strength are measured by the direct tensile test using a specimen with rectangular cross section.

In the case of precast K-UHPC members fabricated at a plant, the standard steam curing process was used to ensure rapid strength development (Park et al. 2015), where $90{ }^{\circ} \mathrm{C}$ is maintained for $48 \mathrm{~h}$. More detailed information on each material has been provided in several previous studies and design recommendations for K-UHPC (Korea Concrete Institute 2012; Park et al. 2015).

\subsection{Test Specimens}

The joints between UHPC segments were realized by shear keys in this study to increase the shear capacity at the joints. The joint types of this study are largely divided into dry joint with or without epoxy and cast-in-place wet joint. Figure 2 shows the details of each joint type for the specimens with two shear keys. In comparison, the specimens with one shear key have a shear key with the same dimensions as that shown in Fig. 2 at the middle height. The shapes of the shear keys were determined by considering the recommendations in the AASHTO specifications $(2003,2017)$. According to the AASHTO specifications, the height of the shear key shall be greater than $30 \mathrm{~mm}$ and twice the diameter of coarse aggregates. Also, the ratio of height to width of the shear key, where the width is measured at the middle height of the shear key, shall remain less than 0.5 in order to reach a desirable failure mode and provide improved strength of the shear keys. The JSCE specifications (2010) have similar provisions. The shape of the shear key with a height of $30 \mathrm{~mm}$ complies with these provisions as shown in the specimens in Fig. 2. However, shear key heights shallower than $30 \mathrm{~mm}$ were also attempted in this study to investigate the improved performance of UHPC. The surface of the shear keys in the test specimens remained smooth without additional treatment according to the usual practice.

In the specimens that have dry joints with epoxy applied, a minimum compressive stress of $0.2 \mathrm{MPa}$ and an average stress of $0.28 \mathrm{MPa}$ were applied across the joint using a temporary prestressing system until the epoxy was cured in accordance with the recommendation in the AASHTO specifications (2017). According to the preliminary tests, the compressive strengths of the

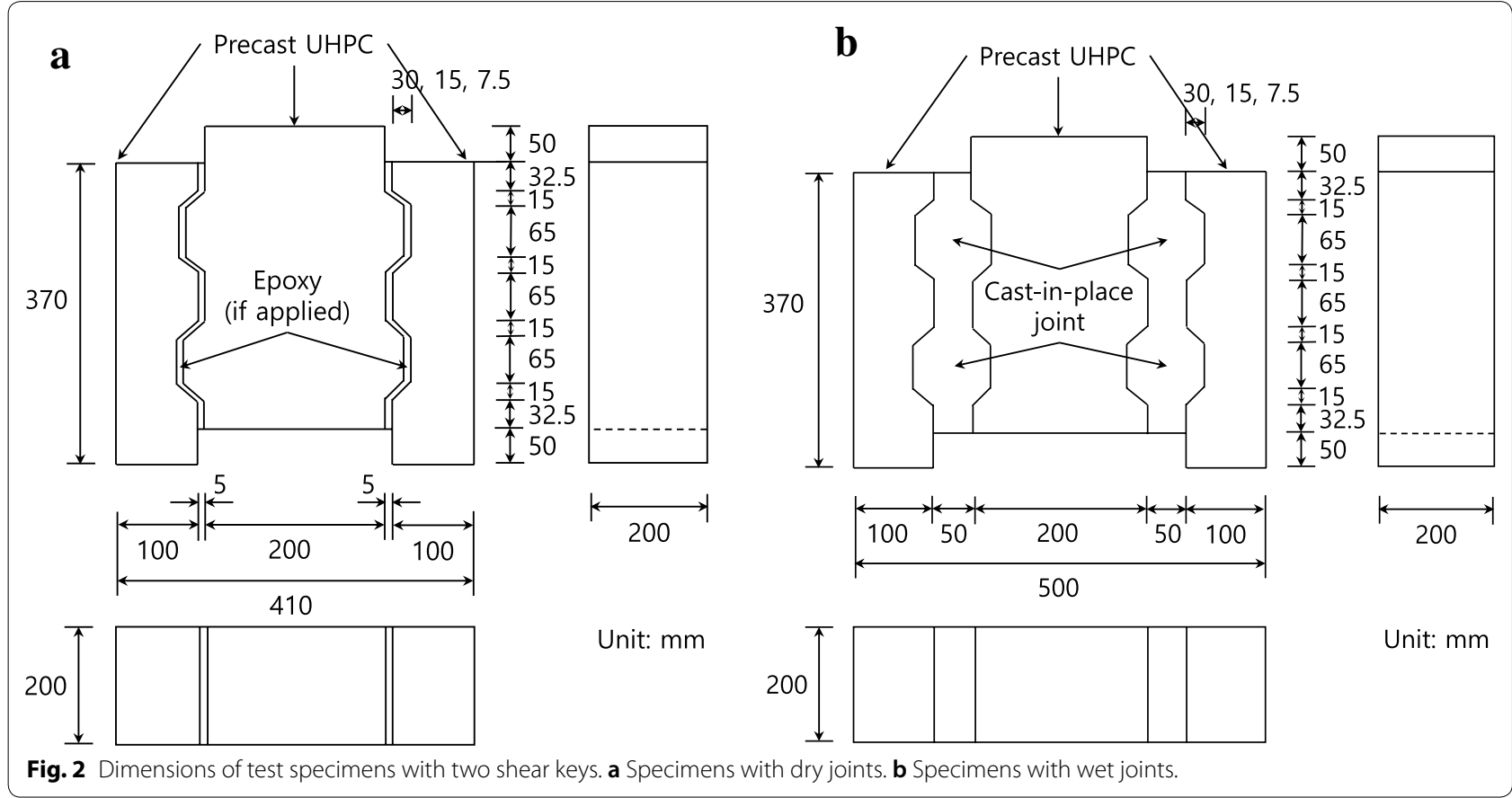


epoxy were 62.5 and $77 \mathrm{MPa}$ at 1 and 7 days after hardening, respectively, and the shear strength of the epoxy was measured as $24.5 \mathrm{MPa}$ at 7 days.

Figure 3 shows the test set-up of the specimens. A lateral load was first applied on the loading plate $(200 \mathrm{~mm} \times 320 \mathrm{~mm}$ with the thickness of $30 \mathrm{~mm}$ ) using a horizontal actuator and was maintained during the loading test. The lateral load simulates the prestress introduced by the prestressing tendons that penetrate the precast UHPC segments in actual construction. In this case, the compressive stresses shown in Table 2 can be introduced by the effective prestressing forces after short-term and long-term losses. The lateral load was introduced to the specimens with wet joint when the filler attained the required strength to resist the compressive stresses in Table 2 after a sufficient curing period. The vertical load was then applied on the loading plate $(200 \mathrm{~mm} \times 200 \mathrm{~mm}$ with the thickness of $30 \mathrm{~mm}$ ) up to the ultimate stage at the loading rate of $0.4 \mathrm{~mm} / \mathrm{min}$. The loading plates were used for distributing the load uniformly on a specimen. Half of the vertical load is applied at each side.

Concrete strain gauges were attached to the specimen surface and displacement gauges were installed to obtain the load-strain relationship and load-displacement relationship, respectively. They were analyzed in the previous studies (Lee et al. 2011a, b).

\subsection{Test Variables}

The test variables of this study are shown in Table 2. Both the dry joint and wet joint were designed. In the dry joint, the effect of epoxy on the strength improvement was investigated. The effectiveness of cast-in-place UHPC as a wet joint filler between UHPC segments was one of the main concerns. Basically, it can be expected that the strength of a joint needs to be similar to that of the main body to avoid the joint becoming a weak part. The

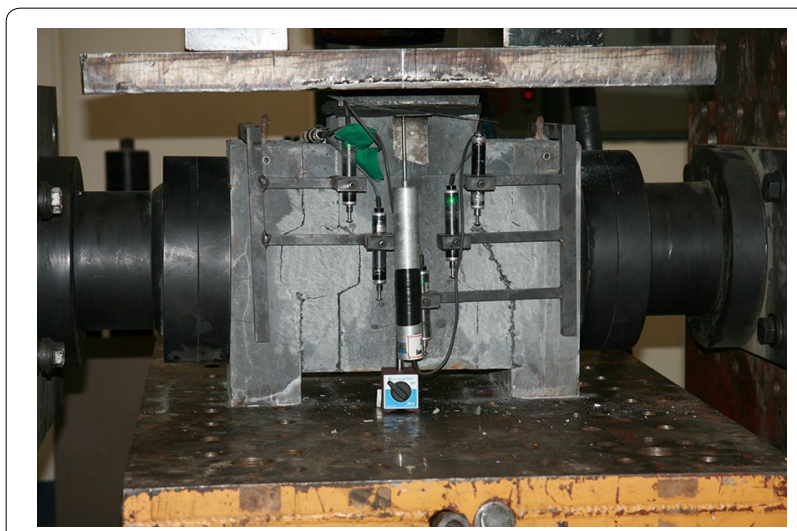

Fig. 3 Set-up of push-off test. number and height of shear keys were considered as variables to investigate the difference of failure mechanism and ultimate capacity at the joint. Three different curing temperatures of the UHPC filler of a wet joint were considered to account for the inferior condition of the construction site in terms of temperature control, when compared to a precast concrete plant where steam curing is available (Park et al. 2015). Lateral compressive stress was applied at several levels to account for various prestress introduced at the joint by the prestressing tendons that connect a number of segments. As explained earlier, shear keys having a $30 \mathrm{~mm}$-height or shorter were used to investigate the improved performance of UHPC.

\section{Analysis of Test Results}

\subsection{Failure Mode}

The failure modes or cracking patterns of the specimens tested in this study varied depending on the test variables. The shape of the vertical load-displacement relationship and the ultimate strength of a specimen were considerably affected by the cracking pattern.

In particular, the height of the shear key had a significant effect on the cracking pattern. When the shear key height was relatively large, diagonal cracks initiated at the lower face of the shear key which led to shear-off failure of the key as shown in Fig. 4a, b. It was often observed as shown in these figures that the shear-off failure occurred in diagonal direction in the wet joint with the dimensions of Fig. 2b, while the base of the shear keys failed in vertical direction in the dry joint. It is also noted in Fig. 4a, $b$ that the steel fibers of the cast-in-place UHPC wet joint and of the main body of UHPC in the dry joint provided additional resistance to the opening of the diagonal cracks. In the case that the shear key was relatively flat, the failure surface tended to occur along the interface as presented in Fig. 4c or at the lower sloped contact face because of excessively high bearing stress.

\subsection{Effect of Test Variables}

\subsubsection{Dry Joint}

3.2.1.1 Number of Shear Keys As shown in Fig. 5a, the failure loads were increased as the number of shear keys increased. The failure load indicates the maximum or ultimate load measured in the actuator. This increased shear strength can be expected because the effective area of interface related to the shear keys was increased and diagonal cracks were distributed in each shear key according to the increased number of shear keys.

3.2.1.2 Lateral Compressive Stress Lateral forces that can be introduced by, for example, prestressing tendons in an actual structure induced a linear increase of the failure load, as presented in Fig. 5b. This is mainly due to 
Table 2 Variables of push-off test.

\begin{tabular}{|c|c|c|c|c|c|c|}
\hline Joint type & $\begin{array}{l}\text { Number } \\
\text { of shear keys }\end{array}$ & Filler & Curing temperature $\left({ }^{\circ} \mathrm{C}\right)$ & $\begin{array}{l}\text { Lateral } \\
\text { compressive stress } \\
\text { (MPa) }\end{array}$ & $\begin{array}{l}\text { Height of shear } \\
\text { key }(\mathrm{mm})\end{array}$ & Specimen ID \\
\hline \multirow[t]{16}{*}{ Dry joint } & 1 & Epoxy & Room temperature ${ }^{a}$ & 2 & 30 & $D-1-E-2-30$ \\
\hline & & & & & 15 & D-1-E-2-15 \\
\hline & & & & & 7.5 & D-1-E-2-7.5 \\
\hline & & & & 4 & 30 & $D-1-E-4-30$ \\
\hline & & & & & 15 & D-1-E-4-15 \\
\hline & & & & & 7.5 & D-1-E-4-7.5 \\
\hline & & & & 8 & 30 & D-1-E-8-30 \\
\hline & & & & & 15 & D-1-E-8-15 \\
\hline & & & & & 7.5 & D-1-E-8-7.5 \\
\hline & & None & & 8 & 30 & $D-1-N-8-30$ \\
\hline & 2 & Epoxy & & 8 & 30 & D-2-E-8-30 \\
\hline & & & & & 15 & D-2-E-8-15 \\
\hline & & & & & 7.5 & D-2-E-8-7.5 \\
\hline & & None & & 8 & 30 & $D-2-N-8-30$ \\
\hline & $0^{b}$ & Epoxy & & 8 & - & D-0-E-8-0 \\
\hline & & None & & 8 & - & $\mathrm{D}-0-\mathrm{N}-8-0$ \\
\hline \multirow[t]{20}{*}{ Wet joint (cast-in-place) } & 1 & UHPC ${ }^{C}$ & 90 & 8 & 30 & W-1-U90-8-30 \\
\hline & & & 70 & 0 & 30 & W-1-U70-0-30 \\
\hline & & & & 0.1 & 30 & W-1-U70-0.1-30 \\
\hline & & & & 2 & 30 & W-1-U70-2-30 \\
\hline & & & & 4 & 30 & W-1-U70-4-30 \\
\hline & & & & 8 & 30 & W-1-U70-8-30 \\
\hline & & & & & 15 & W-1-U70-8-15 \\
\hline & & & & & 7.5 & W-1-U70-8-7.5 \\
\hline & & & & 12 & 30 & W-1-U70-12-30 \\
\hline & & & Room temperature & 8 & 30 & W-1-URT-8-30 \\
\hline & & & & & 15 & W-1-URT-8-15 \\
\hline & & & & & 7.5 & W-1-URT-8-7.5 \\
\hline & & Mortar ${ }^{d}$ & 70 & 8 & 30 & W-1-M70-8-30 \\
\hline & & Concrete $^{e}$ & & & 30 & W-1-C70-8-30 \\
\hline & 2 & UHPC & 70 & 8 & 30 & W-2-U70-8-30 \\
\hline & & & & & 15 & W-2-U70-8-15 \\
\hline & & & & & 7.5 & W-2-U70-8-7.5 \\
\hline & 0 & & & 2 & - & W-0-U70-2-0 \\
\hline & & & & 4 & - & W-0-U70-4-0 \\
\hline & & & & 8 & - & W-0-U70-8-0 \\
\hline
\end{tabular}

a Room temperature $=20 \pm 5^{\circ} \mathrm{C}$

b Number of shear keys $=0$ means the joint with flat interface.

c UHPC: specified compressive strength $=180 \mathrm{MPa}$.

d Mortar: specified compressive strength $=30 \mathrm{MPa}$.

e Concrete: specified compressive strength $=35 \mathrm{MPa}$.

the increased frictional resistance at the interface along with the increased lateral compressive stress which is applied perpendicular to the interface.
3.2.1.3 Height of Shear Key Shear key heights shallower than $30 \mathrm{~mm}$ were attempted, despite their noncompliance with the current specifications (AASHTO 

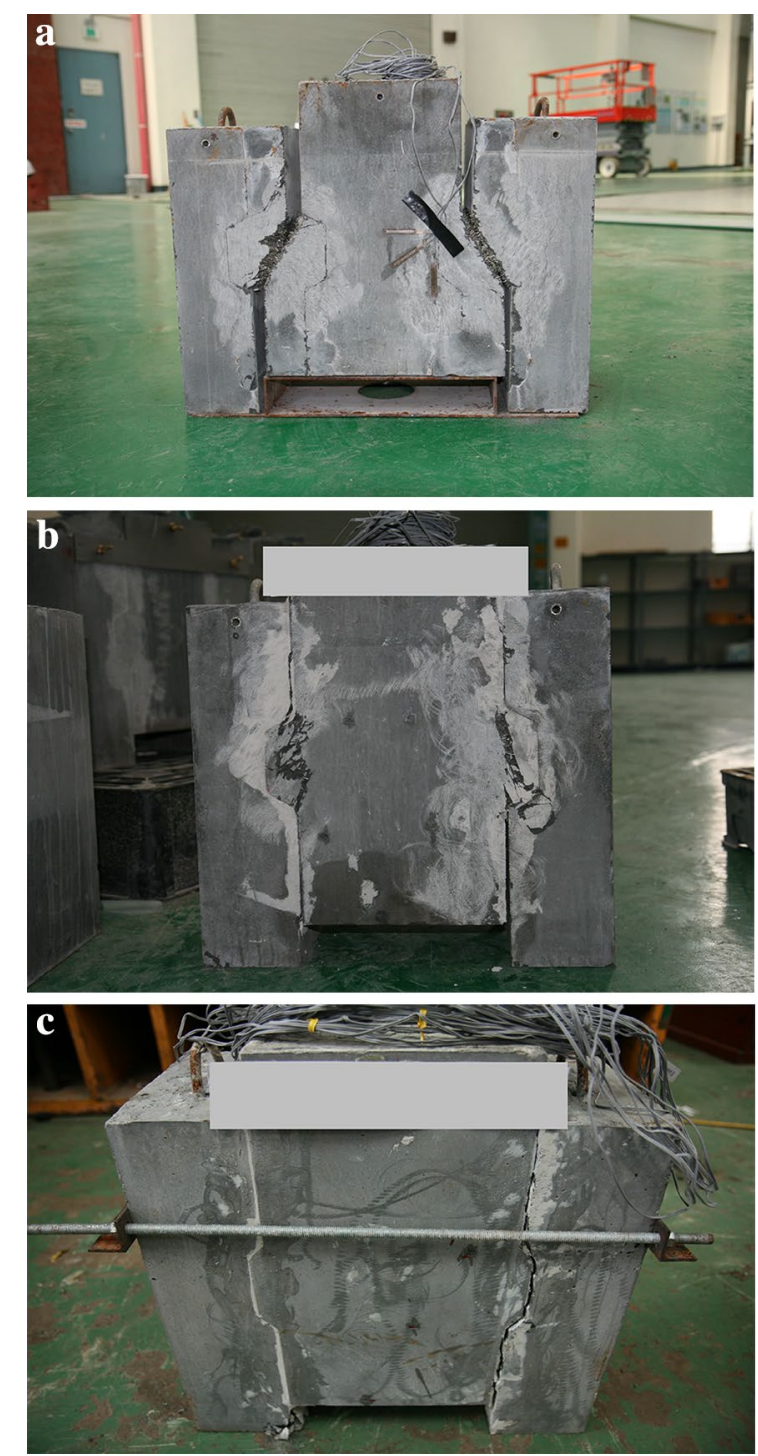

Fig. 4 Failure shape of a specimen. a Diagonal cracks and shear-off (wet joint). b Diagonal cracks and shear-off (dry joint). c Interface debonding.

2003, 2017; JSCE 2010), to investigate the characteristics of UHPC. However, the failure loads were decreased as the shear key height decreased below $30 \mathrm{~mm}$, as shown in Fig. 5c. This indicates that the shear key height is still important in the design of UHPC members and the recommendations of AASHTO $(2003,2017)$ and JSCE (2010) that are based on the experiments of normal strength concrete are also valid to UHPC.

3.2.1.4 Existence of Epoxy It is known that epoxy coating at the interface can improve load-carrying capacity and prevent water leakage. An epoxy-coated specimen
(D-1-E-8-30) showed a slightly higher failure load (6.3\%) compared to a specimen without epoxy coating (D-1-N8-30), as shown in Fig. 5d. However, it appears that the result of small difference cannot be generalized because Fig. 5d only represents the specimens with one shear key. In fact, the specimen with two epoxy-coated shear keys (D-2-E-8-30) attained the maximum load as high as $3336 \mathrm{kN}$, while the non-epoxy specimen with other conditions the same (D-2-N-8-30) resulted in a failure load of $2631 \mathrm{kN}$, which is $21.1 \%$ less than that of D-2-E-8-30. The D-2-E-8-30 specimen may even have a higher failure load since the test was stopped due to the stroke limit of the actuator. Therefore, epoxy can be regarded as effective in increasing the joint shear strength as recommended in the AASHTO specifications (2017).

\subsubsection{Wet Joint}

3.2.2.1 Number of Shear Keys Similarly to the specimens with dry joints, the failure loads were also increased as the number of shear keys increased in the wet joint. When the shear key does not exist, the interface can only resist the shear force by cohesion and friction of the two materials in contact with each other without geometrical contribution of the shear key, which reduces the failure load. When comparing Figs. 5a and 6a, it can be observed that the failure loads of the specimens with one or two shear keys in the dry joint with epoxy and wet joint are similar (2.4 and 5.5\% higher in the dry joint than in the wet joint for one and two shear keys, respectively). These results with the highest compressive stress of $8 \mathrm{MPa}$ imply that when the same number and shape of UHPC shear keys are used, the shear strengths are similar regardless of joint types when a high level of lateral compressive stress is applied. This aspect will be revisited in Sect. 3.2.3.

However, in the case of the specimen with no shear key, the failure load of the dry joint with epoxy was $53.2 \%$ higher than that of the wet joint although the failure modes were similar as the interface debonding in both cases. This phenomenon can be attributed to the higher cohesion of epoxy used in the dry joint than that of the old and new UHPC interface of the wet joint.

\subsubsection{Lateral Compressive Stress A wider range of} lateral compressive stresses were attempted in the specimens with wet joints compared to those with dry joints in order to further investigate the effect of lateral force on shear strength. As shown in Fig. 6b, the failure loads were increased as the lateral compressive stress increased except for one case of $12 \mathrm{MPa}$. The failure load corresponding to the compressive stress of $12 \mathrm{MPa}$ was rather slightly decreased to $2168 \mathrm{kN}$ when compared to $2332 \mathrm{kN}$ for the compressive stress of $8 \mathrm{MPa}$. However, the failure 


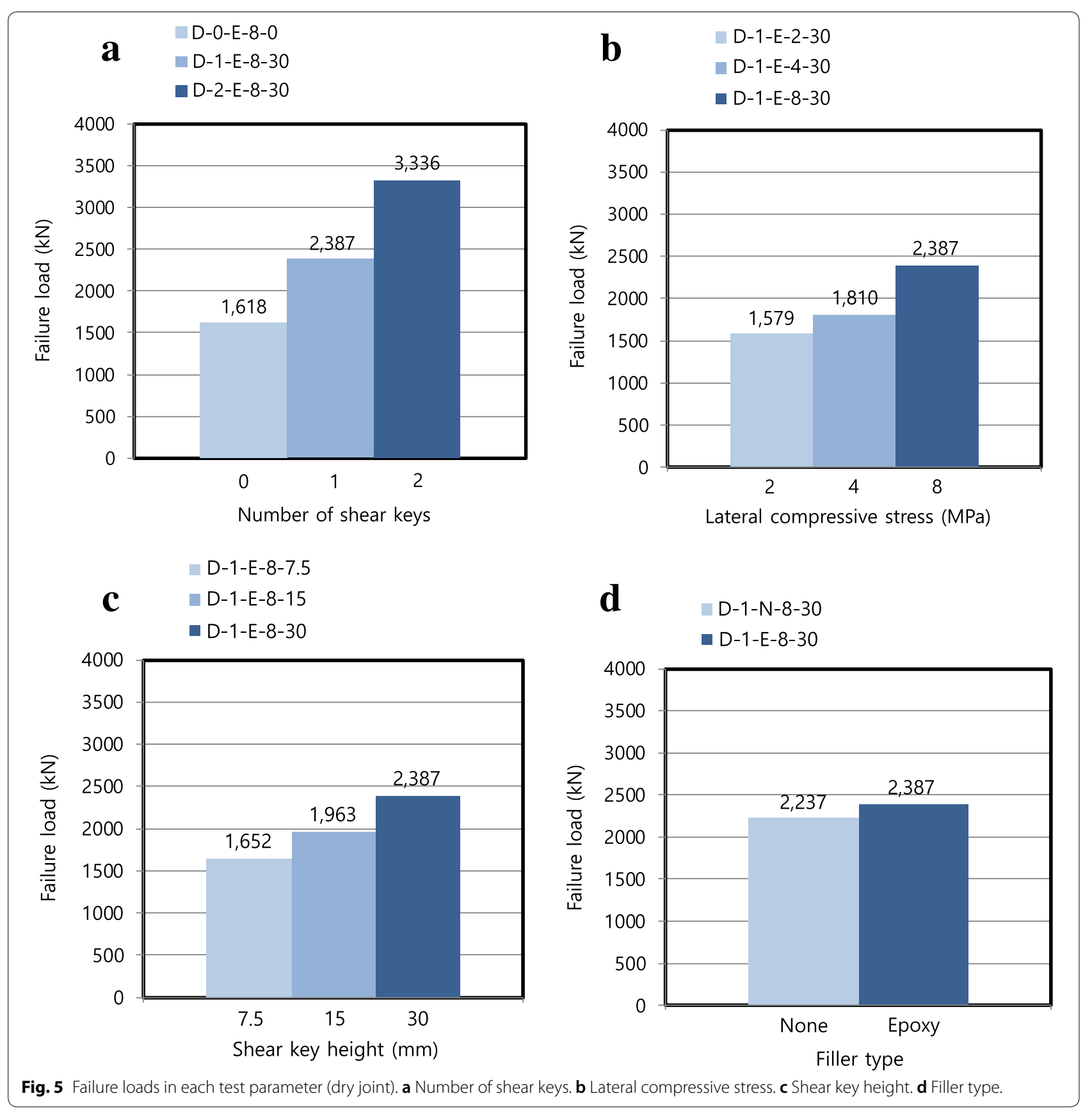

load for the case of $12 \mathrm{MPa}$ was not properly measured since it reached the stroke limit prior to the failure due to excessive lateral force, and thus it was excluded from the analyses in Fig. 6b.

3.2.2.3 Curing Temperature of UHPC High-temperature steam curing at $90{ }^{\circ} \mathrm{C}$ is usually adopted to obtain rapid strength development in precast UHPC fabricated in a favorable condition such as in a factory. However, the curing temperature is often limited in cast-in-place UHPC used for the wet joints of structures at a construction site. This is why curing temperatures of 20 and $70{ }^{\circ} \mathrm{C}$, lower than $90{ }^{\circ} \mathrm{C}$, were also attempted in this study. Park et al. (2015) performed an extensive study on the development of the compressive strength of UHPC affected by curing temperature, duration of curing, moisture condition, etc. They concluded that the specified compressive strength of UHPC can eventually be developed even with a tempera- 

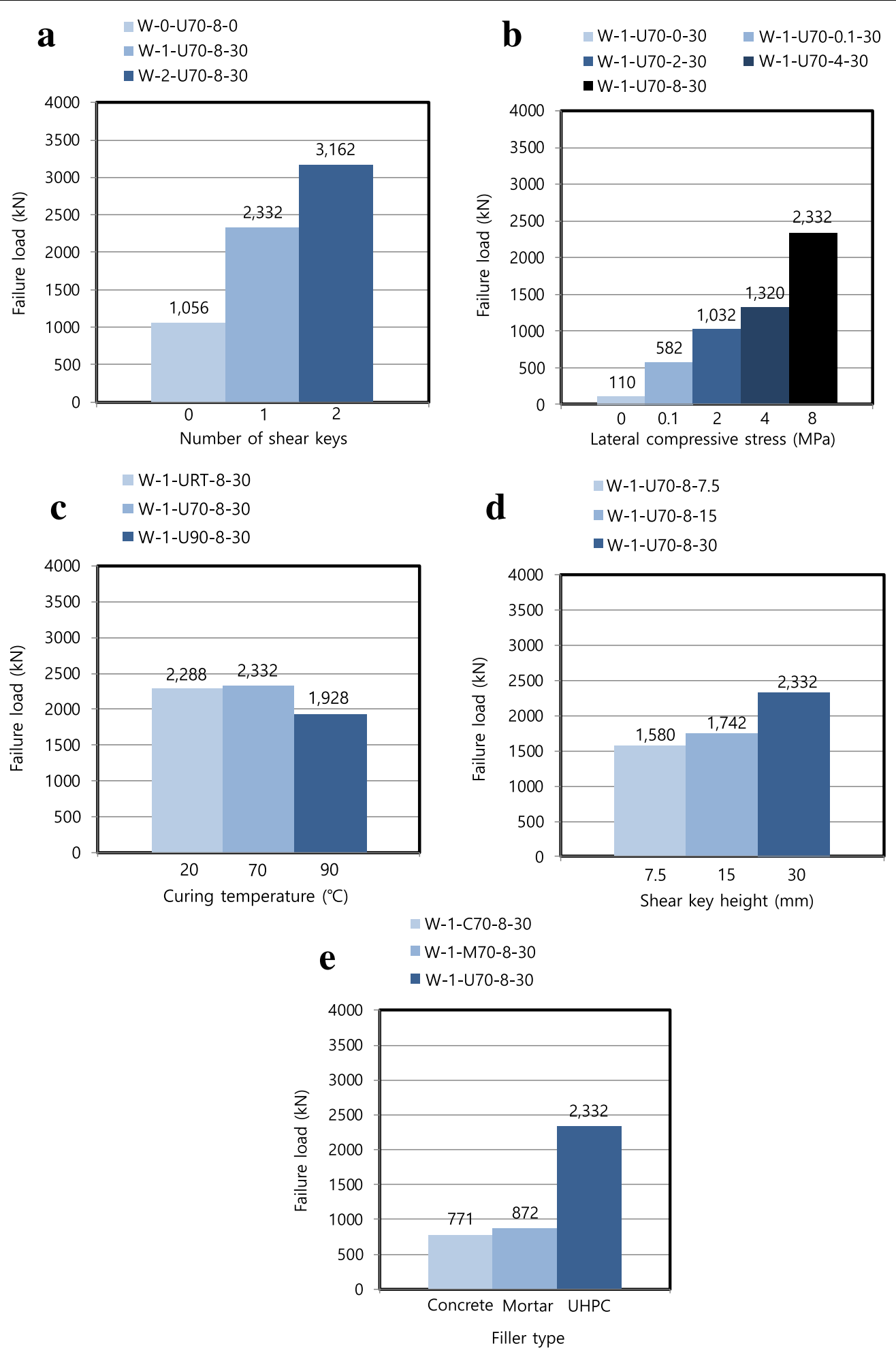

Fig. 6 Failure loads in each test parameter (wet joint). a Number of shear keys. b Lateral compressive stress. c Curing temperature of UHPC. d Shear key height. e Filler type. 
ture lower than $90{ }^{\circ} \mathrm{C}$ if sufficient moisture is provided. Because the specimens of this study were tested in a sufficiently long time after casting the UHPC at the wet joint and the UHPC was subjected to moist curing condition in a constant temperature and humidity chamber with relative humidity of almost $100 \%$, the strengths of the UHPC cured at different temperatures were expected not to vary significantly. This aspect was reflected in the failure loads shown in Fig. 6c. The slight decrease of the failure load at the highest curing temperature of $90^{\circ} \mathrm{C}$ may be due to the side effect observed in a previous study (Park et al. 2015).

3.2.2.4 Height of Shear Key The trend of failure loads as affected by shear key heights was similar to that of dry joints, as shown in Fig. 6d. That is, the failure loads were increased as the shear key height increased. This result reconfirms the validity of the recommendations of AASHTO $(2003,2017)$ and JSCE (2010) for the minimum shear key height of $30 \mathrm{~mm}$.

3.2.2.5 Filler Type The specimen with UHPC filler was approximately three times stronger than that with concrete or mortar filler, as presented in Fig. 6e. These results can be attributed to the difference of the strengths of the fillers. That is, the specified compressive strength of the UHPC was five to six times higher than that of concrete or mortar, as shown in Table 2.

The structural efficiency of a structure fabricated of precast UHPC segments can be well maintained only when the joints between the segments do not become weak points. This can be achieved by casting the UHPC with a similar strength to that of the UHPC segments at the joints instead of casting conventional concrete or mortar.

\subsubsection{Comparison Between Dry Joint and Wet Joint}

Figure 7 compares the failure loads of wet joints with those of dry joints. The wet joints with UHPC filler and the dry joints with epoxy were compared because they can be regarded as representative cases of practical application. When compared to Fig. $6 \mathrm{~b}$ of the wet joint, the case of non-lateral stress was excluded as a special case and the lateral stress of $12 \mathrm{MPa}$ was also excluded because the failure load was not reached in this case as mentioned previously. Figure 7 also shows the corresponding linear regression equations, with the coefficient of determination $\left(R^{2}\right)$ almost the same as unity, representing a strong linear relationship, that can be used to predict the failure load according to lateral compressive stress. In general, the dry joints showed higher failure loads than those of the wet joints to some extent and the difference was greater as the lateral stress decreased. As

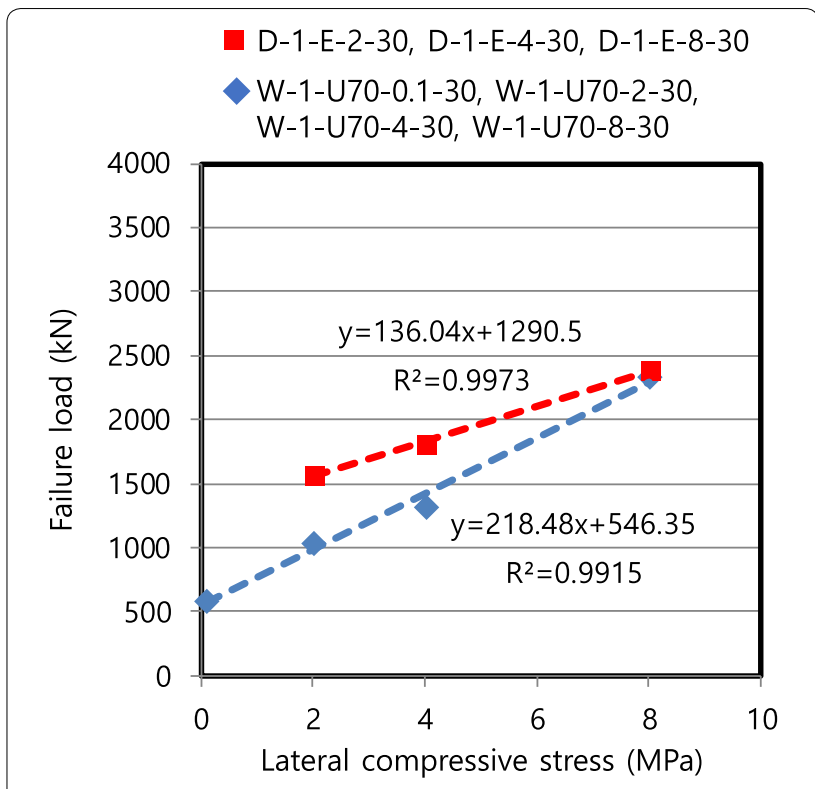

Fig. 7 Comparison of failure loads between dry and wet joints.

a result, the difference was as much as $53 \%$ in the case of the lateral stress of $2 \mathrm{MPa}$.

The reasons for this difference in the failure loads between the two types of joints can be analyzed from two points of view. First, the strength of the cast-inplace UHPC of the wet joint would be prone to slightly decrease when compared to that of precast UHPC due to the unexpected inferior curing condition. Secondly, referring to Fig. 2, the wet joint accompanies more weak points in terms of stress concentration, such as the corners of the shear keys, than those of the dry joint. In fact, the failure mechanism of the wet joint often exhibits diagonal cracks and shear-off that connects two corners of the shear keys as shown in Fig. 4a. Therefore, in the field application of the precast UHPC segments, the dry joint type is more recommended than the wet joint in terms of strength as well as constructability, although both the dry and wet joints are possible options in practice. The mixing and curing of UHPC cast at a construction site can often involve cumbersome tasks and technical difficulties especially when the air temperature is relatively high or low. However, superiority of the joint type needs to be further verified in terms of long-term loading including fatigue.

\section{Comparison of Experiment with Design Provisions}

\subsection{Comparison with Design Formulas}

Many equations that can predict the shear strength at the concrete joint interface in terms of shear transfer mechanism have been proposed and incorporated into various 
design codes. However, most of the equations specified in the codes have been derived from the tests of normal strength concrete. Therefore, this study verifies whether the existing equations can also be extended to the range of ultra-high strength of UHPC. The equations largely consist of two types of resistance: friction and cohesion. However, in many equations, the effect of shear keys is not directly accounted for (AASHTO 2017; CEN 2004; fib 2013), and the shear key geometry can only be reflected as the coefficients of friction or cohesion corresponding to a very rough surface or an indented surface in an indirect way. On the other hand, in a few design equations, the shape of the shear keys is reflected as a separate term in a more detailed manner (AASHTO 2003; JSCE 2004, 2010). Because the effect of shear key geometry, including the number of shear keys, on the shear strength is one of the main concerns in this study, the equations presented in the AASHTO guide specifications (2003) and JSCE recommendations $(2004,2010)$ were analyzed in detail and compared with the test results to verify the applicability of these equations to UHPC.

Equation (1) shows the predictive equation of the AASHTO guide specifications (2003). The form of Eq. (1) is expressed in The International System of Units (SI units) instead of in the US customary units of the original equation. The AASHTO guide specifications state that Eq. (1) can only be applied to the dry joints without epoxy. In comparison, AASHTO LRFD Bridge Design Specifications (2017) only allow either cast-in-place closures or match-cast epoxied joints in the joints of precast segmental bridges. The apparent feature of Eq. (1) is the inclusion of $f_{p c}$ in both terms. That is, the contribution of shear keys to the shear strength is also affected by compressive stress. The constant 0.6 in the second term represents a friction coefficient.

$$
V_{n j}=A_{k} \sqrt{0.006792 f_{c}^{\prime}}\left(12+2.466 f_{p c}\right)+0.6 A_{s m} f_{p c}
$$

where $V_{n j}$ is the nominal joint shear capacity $(\mathrm{N}), A_{k}$ is the area of the base of all keys in the failure plane $\left(\mathrm{mm}^{2}\right)$, $f_{c}^{\prime}$ is the compressive cylinder strength of concrete $(\mathrm{MPa})$, $f_{p c}$ is the compressive stress in concrete (MPa), and $A_{s m}$ is the area of contact between smooth surfaces on the failure plane $\left(\mathrm{mm}^{2}\right)$.

On the other hand, the equation in the JSCE recommendations $(2004,2010)$ is shown in Eq. (2). The original form of Eq. (2) was first presented in a previous edition of Standard Specifications for Concrete Structures (JSCE 2010) and it was referred to in Recommendations for Design and Construction of Ultra High Strength Fiber Reinforced Concrete Structures (JSCE 2004). Equation (2) features the inclusion of $f_{c d}^{\prime}$ in both terms. This implies that the concrete strength can contribute not only to the strength of the shear keys but also to the friction characteristics in some circumstances.

$$
V_{c w}=\mu f_{c d}^{\prime b} \sigma_{n d}^{1-b} A_{c c}+0.1 A_{k} f_{c d}^{\prime}
$$

where $V_{c w}$ is the shear strength $(\mathrm{N}), \mu$ is the average friction coefficient of solid contact $(0.45), f_{c d}^{\prime}$ is the design compressive cylinder strength $(\mathrm{MPa}), \sigma_{n d}$ is the average compressive stress which acts perpendicular to shear plain (MPa), $A_{c c}$ is the area of shear plane in compression zone $\left(\mathrm{mm}^{2}\right), b$ is the coefficient indicating plane configuration (range of $0-1$ and 0.5 in the case of the joint of precast members with an adhesive agent), and $A_{k}$ is the area of compressive side of shear keys $\left(\mathrm{mm}^{2}\right)$. Note that the definition of $A_{c c}$ does not coincide with that of $A_{s m}$ of Eq. (1), while the meaning of $A_{k}$ is the same as that of $A_{k}$ of Eq. (1). The friction coefficient of 0.45 is $25 \%$ less than 0.6 used in Eq. (1).

The test results were compared in Fig. 8 with the predictions by Eqs. (1) and (2) in various ways depending on the test variables. Note that the joint shear strength is half the failure load in this test set-up. The shear key height is not considered as a variable in either Eq. (1) or (2). Although the AASHTO equation of Eq. (1) was originally intended for a dry joint without epoxy resin, the test data other than this joint type were also compared with Eq. (1) to investigate the applicability of Eq. (1). Even though the coefficient $b$ of Eq. (2) plays an important part in the shear strength, the only value presented in these recommendations is 0.5 for the joint with an adhesive agent such as epoxy. Therefore, referring to a few previous studies (Shin 2016; Watanabe et al. 2007), 0.4 was employed for the wet joint, while zero was assumed for the dry joint without epoxy. In Eq. (2), $\sigma_{n d}$ was considered as it is without $50 \%$ reduction for additional safety as presented in the JSCE specifications (2010). Also, $f_{c d}^{\prime}$ originally referred to the design compressive strength that can be obtained by dividing the characteristic compressive strength by a material partial safety factor according to the concept of the limit state design. However, the specified (characteristic) compressive strength of the UHPC of $180 \mathrm{MPa}$ was used instead in these analyses for the purpose of comparing with the test data. Besides, $A_{k}$ in Eqs. (1) and (2) is $0,19,000$, and $38,000 \mathrm{~mm}^{2}$ for zero, one, and two shear keys, respectively. $A_{s m}$ in Eq. (1) is $64,000,45,000$, and $26,000 \mathrm{~mm}^{2}$ for zero, one, and two shear keys, respectively, while $A_{c c}$ in Eq. (2) has a constant value of $64,000 \mathrm{~mm}^{2}$ regardless of the number of shear keys.

As shown in Fig. 8a, the AASHTO equation underestimated the shear strengths in all the joint types, including the dry joint without epoxy. The values 

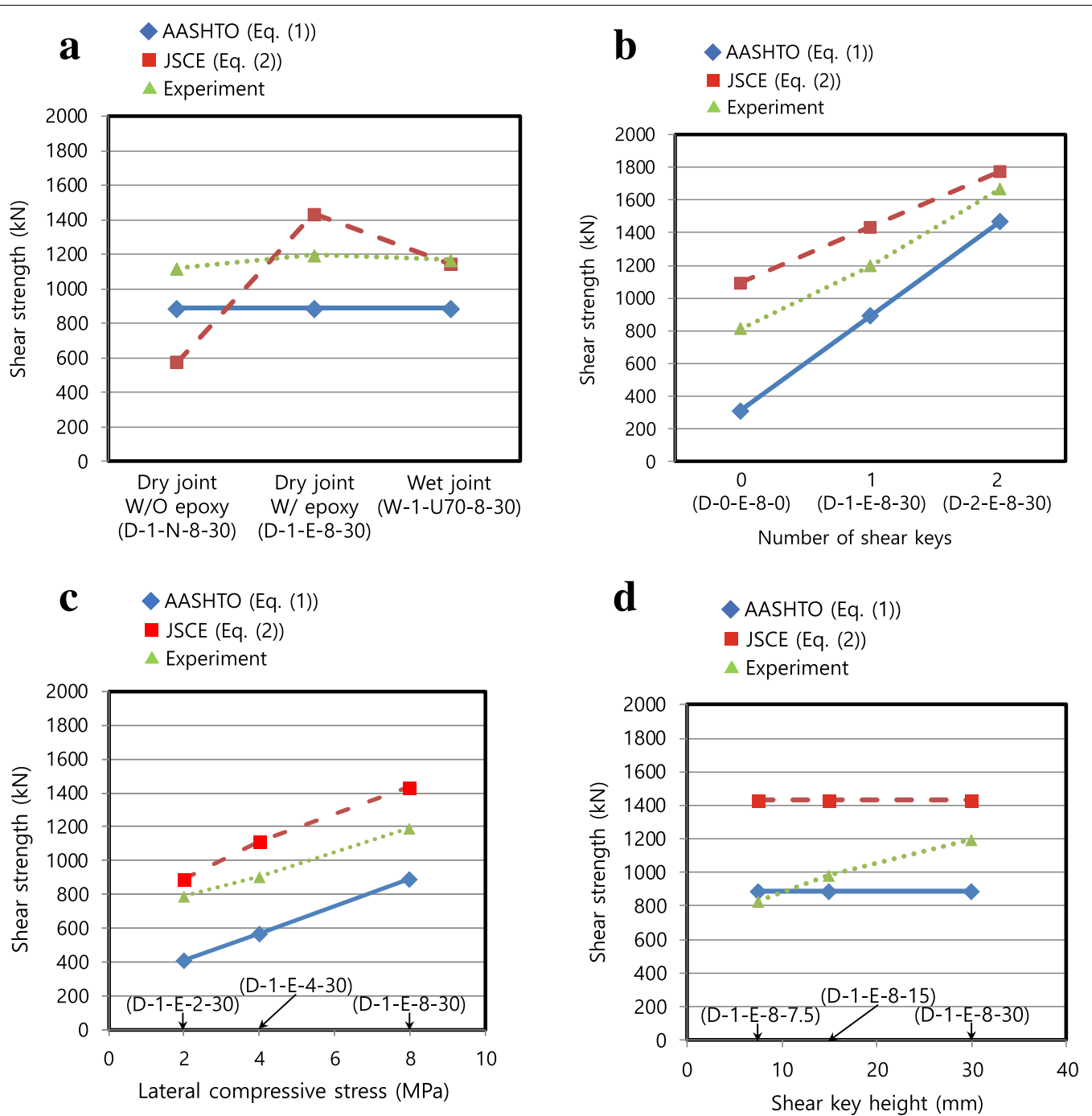

Fig. 8 Comparison of experimental data with predictive equations. a Joint type. b Number of shear keys. c Lateral compressive stress. d Shear key height.

resulting from the JSCE equation significantly differed depending on the joint type, and were in good agreement with the test data of the wet joint.

Increasing trend of the shear strength according to the number of shear keys was adequately implemented in Eqs. (1) and (2) as shown in Fig. 8b. The test data as well as the predictive values were almost in linear relation to the number of shear keys. However, the AASHTO equation underestimated the strengths, whereas the JSCE equation overestimated the strengths. If the exponential coefficient $b$ of the JSCE equation was slightly adjusted, the predicted strengths would approach the experimental data. This type of versatility is one of the advantages of the JSCE equation, although some tests need to be performed to select a reasonable coefficient. This issue is covered in the following section.

Figure $8 \mathrm{c}$ shows the increasing trend of the shear strength both in the test and prediction as the lateral compressive stress increased. Similar to Fig. 8b, the AASHTO equation tended to underestimate the strengths, while the JSCE equation overestimated the strengths. The JSCE equation was not in linear relation to the lateral compressive stress, as can be expected in the form of Eq. (2).

As mentioned previously, because the height of the shear key is not reflected as a variable in either Eq. (1) or Eq. (2), the trends somewhat differed between the test and prediction, as shown in Fig. 8d. Judging from the context of the relevant specifications, these 
equations were derived based on the assumption that the key height is more than $30 \mathrm{~mm}$. Nevertheless, the shear strengths for the shear key height of $30 \mathrm{~mm}$ also differed considerably.

\subsection{Improvement of a Predictive Equation}

The analysis results of Sect. 4.1 show that the two representative predictive equations for the joint shear strength do not correctly estimate the experimental results of this study. The AASHTO equation of Eq. (1) originally developed for the dry joint without epoxy largely underestimated the strengths measured in various joint conditions. Figure 8a shows that the AASHTO equation may even result in a lower value than that measured in a dry joint without epoxy. Therefore, it should be careful to apply the AASHTO equation to estimate the joint shear strength of UHPC because this equation shows too much conservatism. Furthermore, Eq. (1) does not include a coefficient that can be adjusted to match the test results of UHPC.

On the other hand, the JSCE equation of Eq. (2) largely overestimated the shear strengths of the dry joints with epoxy. For the wet joints, although Fig. 8a shows good agreement with the test for the compressive stress of $8 \mathrm{MPa}$ (W-1-U70-8-30), further analyses revealed that Eq. (2) overestimated the strengths for other compressive stresses (33.8 and $31.8 \%$ for W-1-U70-2-30 and W-1-U70-4-30, respectively). Judging from the form of Eq. (2), the overestimation can be mainly attributed to $f_{c d}^{\prime}$ included in the first term that refers to the contribution of friction. Specifically, it seems that the first term is highly overestimated when the concrete strength is within the ultra-high range. However, a margin for improvement can be found in Eq. (2). That is, coefficient $b$ can be adjusted to match the test results of UHPC because the previously recommended values of $b$ ( 0.4 for wet joint and 0.5 for dry joint with epoxy) were derived from the concrete specimens with the range of normal strengths.

Figure 9 presents an example of the possible improvement of Eq. (2) in the case of the dry joint with epoxy when compared to Fig. 8b, c in terms of number of shear keys and lateral compressive stress, respectively. The coefficient $b$ was revised to 0.4 from the original value of 0.5 for the application of epoxy. As a result, the predictive values showed good agreement with the measured values with sufficient accuracy. The improved predictive values even showed slight conservatism, which is desirable from the perspective of safety. The differences from the test data were only $1.1,4.3$, and $11.0 \%$ for D-0-E-8-0, D-1-E-8-30, and D-2-E-8-30, respectively, in Fig. 9a. The differences were still as small as $12.5,3.9$, and $4.3 \%$ for D-1-E-2-30, D-1-E-4-30, and D-1-E-8-30, respectively, in Fig. 9b.

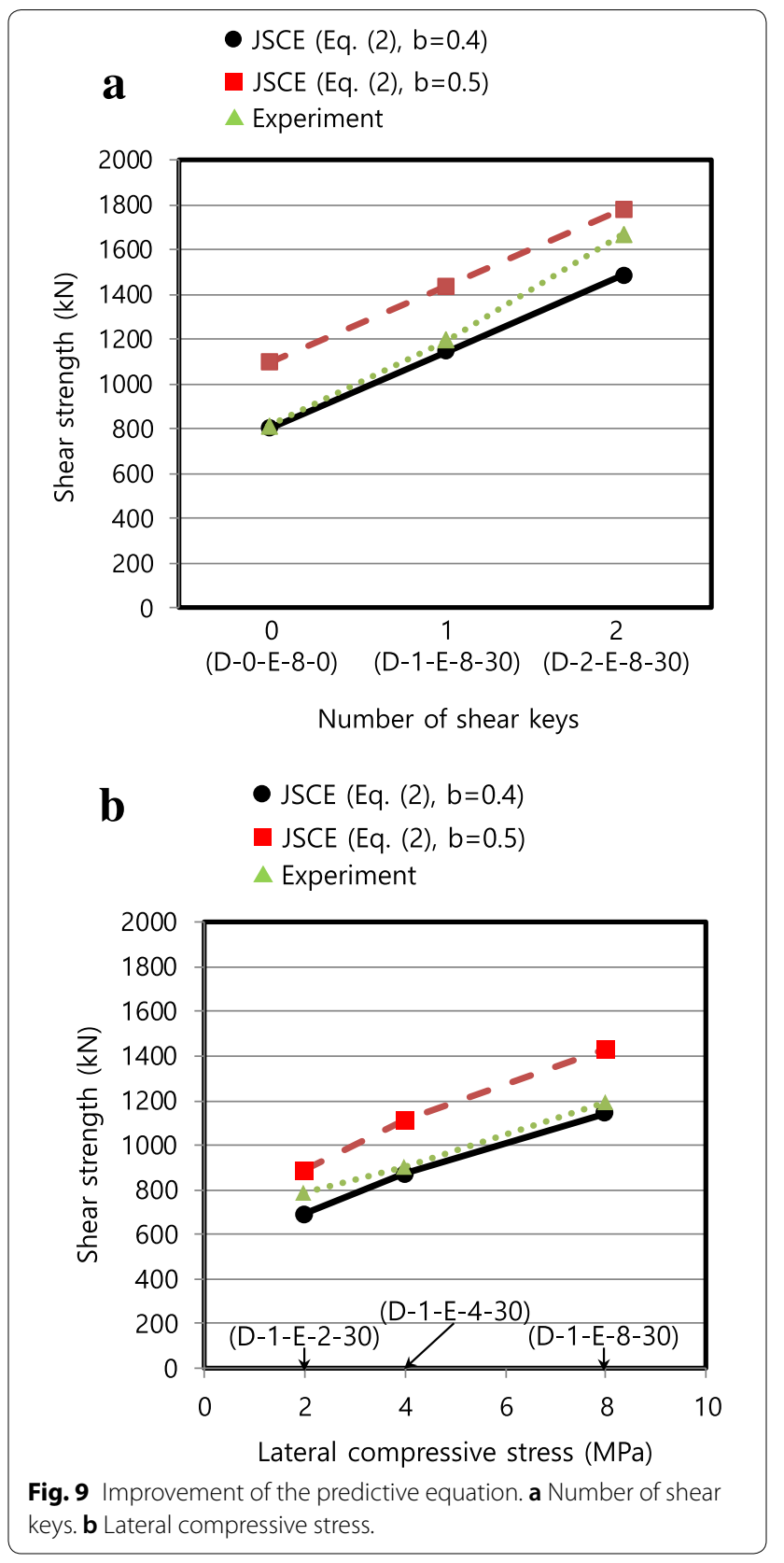

However, the revised JSCE equation still overestimated the shear strengths for the shear key height lower than $30 \mathrm{~mm}$ (38.3 and 16.4\% for D-1-E-8-7.5 and D-1-E-8-15, respectively). This indicates that the minimum shear key height of $30 \mathrm{~mm}$ specified in AASHTO $(2003,2017)$ and JSCE (2010) should be ensured if the revised JSCE equation is to be effective.

On the other hand, the analyses of wet joints showed that it was hard for the equation to entirely approach the test data simply by adjusting the value of coefficient $b$ because the trends of overestimation and 
underestimation coexisted when compared to original JSCE equation with $b=0.4$. As was mentioned previously, $b=0.4$ is not specified in JSCE specifications (2010) but was proposed in some studies (Shin 2016; Watanabe et al. 2007), in which Watanabe et al. (2007) applied UHPC filler with specified compressive strength of $180 \mathrm{MPa}$. Therefore, it would be desirable to further investigate the validity of $b=0.4$ for the wet joint with more accumulated test data before discussing the revision of the coefficient $b$ for UHPC filler.

In the application of this equation to the actual design of UHPC structures, additional safety factors such as material factor and member factor are employed according to the concept of the limit state design of the JSCE specifications (2010) in order to ensure sufficient safety by overcoming a range of uncertainties.

\section{Conclusions}

The interface shear behavior at the joints of UHPC segments was experimentally investigated by push-off tests in this study with the test variables including joint type, number and height of shear keys, type of filler, curing temperature, and lateral compressive stress. Based on the results of this study, the following conclusions were drawn:

(1) The failure loads were increased as the number of shear keys, lateral compressive stress, and height of the shear key increased both in the dry joint applied with epoxy and in the wet joint filled with UHPC. Therefore, the trend of the joint shear strengths of UHPC as affected by various parameters was similar to that of normal strength concrete. In the wet joint type, the specimen with UHPC filler was approximately three times stronger than that with concrete or mortar filler. This indicates that the structural efficiency of a UHPC structure made of precast segments can be ensured when the joints maintain an equivalent strength to that of the main body. Also, shear key height was still important in the design of the UHPC structures in terms of shear strength, and the existing recommendations of at least $30 \mathrm{~mm}$ height appear to be effective.

(2) The equations presented in the AASHTO guide specifications and JSCE recommendations were compared with the test data to verify the applicability of these equations to UHPC, which were originally derived from the tests of normal strength concrete. The increasing trend of the shear strength is implemented in these equations as the number of shear keys and lateral compressive stress increase. However, for the UHPC, while the AASHTO equation tended to underestimate the joint shear strength, the JSCE equation overestimated the strength, especially at the dry joint with epoxy and at the wet joint filled with UHPC.

(3) The overestimation of the JSCE equation can be mainly attributed to the concrete strength included in the term related to frictional resistance. This term is highly overestimated when the concrete strength falls into the ultra-high range. An improvement was proposed in this study by adjusting a coefficient of the JSCE equation. That is, in the case of the dry joint with epoxy, the coefficient was revised to be appropriate for UHPC instead of the original value previously proposed for normal strength concrete. As a result, the predictive values showed fairly good agreement with the measured values with accuracy and conservatism. In this way, in order to disseminate the UHPC for practical use in construction sites, efforts need to be made to verify the applicability of the existing design formulas which were proposed for ordinary concrete and to modify these formulas, if necessary, by analyzing the accumulated experimental data of UHPC.

\section{Authors' contributions}

WJC conceived, designed and performed the experiments. YJK supervised this project as a principal investigator. SJJ analyzed the data and wrote the paper. All authors read and approved the final manuscript.

\section{Author details \\ ${ }^{1}$ Structural Engineering Research Institute, Korea Institute of Civil Engineering and Building Technology, 283, Goyang-daero, Ilsanseo-gu, Goyang-si, Gyeo- nggi-do 10223, Republic of Korea. ${ }^{2}$ Department of Civil Systems Engineering, Ajou University, 206, Worldcup-ro, Yeongtong-gu, Suwon-si, Gyeonggi-do 16499, Republic of Korea.}

\section{Acknowledgements}

This work is supported by a grant from a Strategic Research Project "Development of Safety Improvement Technology for Bridge Weak Connection and Seismic Equipment to Secure Evacuation and Recovery Route in Earthquake" of the KICT (Korea Institute of Civil engineering and building Technology). The authors express their gratitude for the support.

\section{Competing interests}

The authors declare that they have no competing interests.

\section{Publisher's Note}

Springer Nature remains neutral with regard to jurisdictional claims in published maps and institutional affiliations.

Received: 31 January 2018 Accepted: 14 July 2018

Published online: 24 September 2018

\footnotetext{
References

American Association of State Highway and Transportation Officials (AASHTO) (2003). Guide specifications for design and construction of segmental concrete bridges (2nd ed.). Washington, D.C.: AASHTO.

American Association of State Highway and Transportation Officials (AASHTO) (2017). AASHTO LRFD bridge design specifications (8th ed.). Washington, D.C.: AASHTO.
} 
European Committee for Standardization (CEN). (2004). Design of concrete structures (Eurocode 2). Brussels: CEN.

Ishii, T., Nishio, H., Matsuyama, T., Miyajima, A., Yokohata, K., Gotou, M., Xin, J., \& Hirai, Y. (2008). Manufacture and construction of a PC through girder type pedestrian bridge using ultra high strength fiber reinforced concrete. In Proceedings of 8 th international symposium on utilization of high-strength and high-performance concrete (pp. 1270-1275). Tokyo.

Japan Society of Civil Engineers (JSCE). (2004). Recommendations for design and construction of ultra high strength fiber reinforced concrete structures (draft). Tokyo: JSCE.

Japan Society of Civil Engineers (JSCE). (2010). Standard specifications for concrete structures-2007 "design". Tokyo: JSCE.

Kaneko, Y. (1992). Modelling of shear-off failure of concrete: Fracture mechanics approach. Ph.D. Dissertation, Massachusetts Institute of Technology, Massachusetts.

Korea Concrete Institute (KCl). (2012). Design recommendations for ultra-high performance concrete K-UHPC, KCl-M-12-003. Seoul: KCl.

Korea Institute of Civil Engineering and Building Technology (KICT). (2012). Development of design and construction system technology for hybrid cable stayed bridge, KICT 2012-075. Goyang-si: KICT.

Lee, C. H., Chin, W. J., Choi, E. S., \& Kim, Y. J. (2011a). An experimental study on the joints in ultra high performance precast concrete segmental bridges. Journal of the Korea Concrete Institute, 23(2), 235-244.

Lee, C. H., Kim, Y. J., Chin, W. J., \& Choi, E. S. (2011 b). Experimental study on the shear behavior of ultra high performance precast PSC bridge joint with joint type and lateral force. Journal of the Korean Society of Civil Engineers, 31(5A), 379-387.

Matsubara, N., Ohno, T., Sakai, G., Watanabe, Y., Ishii, S., \& Ashida, M. (2008). Application of a new type of ultra high strength fiber reinforced concrete to a prestressed concrete bridge. In Proceedings of 2nd international symposium on ultra high performance concrete (pp. 787-794). Kassel.

Mohsen, A. I., \& Hiba, A. A. (2007). Structural behavior of single key joints in precast concrete segmental bridges. Journal of Bridge Engineering, 12(3), 315-324.

Park, J. S., Kim, Y. J., Cho, J. R., \& Jeon, S. J. (2015). Early-age strength of ultrahigh performance concrete in various curing conditions. Materials, 8(8), 5537-5553.

Park, S. Y., Kim, S. T. Cho, J. R. Lee, J. W., \& Kim, B. S. (2013). Trial construction of UHPC highway bridge. In Proceedings of RILEM-fib-AFGC international symposium on ultra-high performance fibre-reinforced concrete (UHPFRC 2013) (pp. 371-377). Marseille.

Shamass, R., Zhou, X., \& Alfano, G. (2014). Finite-element analysis of shear-off failure of keyed dry joints in precast concrete segmental bridges. Journal of Bridge Engineering, 20(6), 04014084.

Shin, J. (2016). Ultra-high performance concrete (UHPC) precast segmental bridges_Flexural behaviour and joint design. Ph.D. Dissertation, Hamburg University of Technology, Hamburg.

The International Federation for Structural Concrete (fib). (2013). fib model code for concrete structures 2010. Lausanne: fib.

Turmo, J., Ramos, G., \& Aparicio, A. C. (2006). Shear strength of dry joints of concrete panels with and without steel fibers: Application to precast segmental bridges. Engineering Structures, 28(1), 23-33.

Watanabe, N., Musha, H., \& Yoshinaga, K. (2007). Design and performance tests for bridge using ultra high strength fiber reinforced concrete. In Proceedings of 23rd US-Japan bridge engineering workshop. Tsukuba.

\section{Submit your manuscript to a SpringerOpen ${ }^{\circ}$ journal and benefit from:}

- Convenient online submission

$\checkmark$ Rigorous peer review

- Open access: articles freely available online

- High visibility within the field

- Retaining the copyright to your article

Submit your next manuscript at $\mathbf{s p r i n g e r o p e n . c o m ~}$ 